Special issue in honor of Prof. George C. Papageorgiou

\title{
Variability of the photosynthetic machinery tolerance when imposed to rapidly or slowly imposed dehydration in native Mediterranean plants
}

\author{
E. KOUTRA*, C. CHONDROGIANNIS ${ }^{* *}$, and G. GRAMMATIKOPOULOS**,+ \\ Laboratory of Biochemical Engineering \& Environmental Technology (LBEET), Department of Chemical \\ Engineering, University of Patras, Patras, Greece* \\ Laboratory of Plant Physiology, Department of Biology, University of Patras, 26504 Patras, Greece**
}

\begin{abstract}
Dehydration affects the photosynthetic apparatus. The impact of dehydration on photosynthesis was assessed in twelve Mediterranean species representing different growth forms. Rapid and slow dehydration experiments were conducted to (1) compare the impact of water stress among species and growth forms, (2) rank species according to their drought tolerance. Rapid dehydration reduced the electron transport up to PSI, the reduction being linearly related to leaf relative water content (RWC), except for the deciduous species. Specific energy fluxes per reaction center and maximum photochemical activity of PSII remained relatively stable until 10-30\% RWC. The modification pattern of the studied parameters was similar for all the growth forms. Slow rehydration increased specific energy fluxes and decreased quantum yields. The dehydration pattern was similar among growth forms, while the recovery pattern was species-specific. Drought tolerance ranking through drought factor index was relatively modified with the integrated biomarker response method.
\end{abstract}

Keywords: drought factor index; integrated biomarker response; JIP-test; photosynthesis; plant growth forms; water stress.

\section{Introduction}

Plant species of semi-arid areas confront water shortage periods of varying intensity and duration (Galmés et al. 2012, Flexas et al. 2014). Drought, in regions with the Mediterranean climate, coexists with high temperatures and high-light intensities, during the prolonged summer period. The integrated result of these multiple stressors is a complex ecophysiological response from the different species according to their repertoire of adjustments to the prevailing environmental conditions (Grammatikopoulos and Manetas 1994, Nogués and Alegre 2002, Galmés et al.

\section{Highlights}

- Rapid dehydration affected electron flow up to the PSI acceptor side

- Growth forms showed different modifications during recovery

- Drought tolerance ranking improved through an index integrating many parameters
Received 4 October 2021

Accepted 12 January 2022

Published online 23 February 2022

${ }^{+}$Corresponding author

phone: +30 2610996771

e-mail: grammati@upatras.gr

Abbreviations: $\mathrm{Chl}$ - chlorophyll; DFI - drought factor index; DM - dry mass; ETR - electron transport rate; $\mathrm{F}_{0}$ - minimal fluorescence yield of the dark-adapted state; $F_{m}$ - maximal fluorescence yield of the dark-adapted state; $F M$ - fresh mass; $F_{v}$ - variable fluorescence; $\mathrm{F}_{\mathrm{v}} / \mathrm{F}_{\mathrm{m}}$ - maximal quantum yield of PSII photochemistry; IBR - integrated biomarker response; LED - light-emitting diode; OEC oxygen-evolving complex; OJIP - polyphasic Chl $a$ fluorescence rise kinetics (O-step: at $\mathrm{t} \cong 0$, J-step: at $\mathrm{t} \cong 2 \mathrm{~ms}, \mathrm{I}$-step: at $\mathrm{t} \cong 30 \mathrm{~ms}$, P-step: peak of the rise kinetics); PDI - photochemical drought index; $\mathrm{PI}_{\mathrm{ABS}}$ - performance index on an absorption basis; $\mathrm{PI}_{\text {total }}-$ total performance index measuring the performance up to the PSI end electron acceptors; RC - reaction centre; RH - relative humidity; RWC - relative water content; TM - turgid mass; $\mathrm{V}_{\mathrm{K}} / \mathrm{V}_{\mathrm{J}}$ - relative amplitude of K-band, related to oxygen-evolving complex inactivation; $\delta \mathrm{R}_{0}$ - efficiency/probability with which an electron from $\mathrm{Q}_{\mathrm{B}}$ is transferred until PSI acceptors; $\varphi \mathrm{E}_{0}-$ quantum yield of electron transport flux from $\mathrm{Q}_{\mathrm{A}}$ to PQ; $\varphi \mathrm{P}_{0}$ - maximum quantum yield of primary PSII photochemistry; $\varphi \mathrm{R}_{0}$ - quantum yield of electron transport flux from $\mathrm{Q}_{\mathrm{A}}$ to the final PSI acceptors; $\psi \mathrm{E}_{0}$ - efficiency/probability with which a PSII trapped electron is transferred from $\mathrm{Q}_{\mathrm{A}}$ to $\mathrm{Q}_{\mathrm{B}}$.

Conflict of interest: The authors declare that they have no conflict of interest. 
2007, Koller et al. 2013). Water stress poses stomatal and nonstomatal restrictions on plant photosynthesis affecting photochemical and metabolic reactions (Flexas and Medrano 2002, Lawlor and Cornic 2002, Chaves et al. 2009, Lawlor and Tezara 2009), while the crucial role of mesophyll conductance has also been recognized (Flexas et al. 2012). As a consequence, plant reactions vary and include long-term and short-term adjustments in their morphology, anatomy, physiology, biochemistry, and biophysics (Chaves et al. 2003).

Photochemistry can be considered as one of the components which participate in the nonstomatal limitation of photosynthesis under various abiotic stresses. It is usually influenced by feedback regulation mechanisms that serve coordination of the energy-producing photochemistry procedure and the energy-utilizing biochemical procedures which are earlier affected during the dehydration process. However, photochemistry can also be directly affected by water stress. The photochemical activity was generally more resistant to water stress than biochemical activity or diffusion procedures, under high or moderate water content (50-95\%) in most of the studied species. Yet, crops and species of temperate climates experience reductions in electron transport rates and photochemistry yields at earlier stages of leaf dehydration than native plants of arid or semi-arid environments (Lawlor and Cornic 2002). Field measurements alone, although reflect the real responses of a plant during the drought period, are not sufficient to distinguish between direct and indirect effects on photosynthesis due to co-change of other crucial environmental parameters like temperature. The sensitivity of photosynthesis to dehydration in terms of maximum photosynthetic rates during summer or in terms of minimum water potential at which net photosynthesis remains positive has been studied in different Mediterranean species.

Chlorophyll (Chl) prompt fluorescence transient analysis (JIP-test) has been continuously improved in the last ten years to estimate the responses of the photosynthetic machinery to various stresses, step by step, distinguishing the different phases of energy flow through the photosystems (Strasser et al. 2004, Kalaji et al. 2016). There is an increasing interest for modifications of fast fluorescence induction transients by water stress and various crop plants have been studied the last years (Oukarroum et al. 2007, 2009; Redillas et al. 2011, Goltsev et al. 2012, Gomes et al. 2012, Guha et al. 2013). Native plants, such as desert scrub species (van Heerden et al. 2007), a resurrection plant (Strasser et al. 2010), and Quercus species (Bussotti 2004, Koller et al. 2013), have also been used in some case studies. The parameters that were most affected by dehydration were those related to yields and probabilities of electron flow through photosystems.

Since the introduction of the JIP-test (Strasser et al. 2000, Tsimilli-Michael and Strasser 2008), it was mentioned the need for some general performance indices (PIs) which would include more than one $\mathrm{Chl} a$ fluorescence parameter. At the same time, Beliaeff and Burgeot (2002),
Broeg and Lehtonen (2006), and Ferreira et al. (2015) introduced an alternative approach to making the most of any multiparametric data for the detection of stress impact on plants, namely the integrated biomarker response (IBR) tool. Recently, the IBR approach was used for the creation of a photochemical stress index (PSI), which integrated several parameters extracted from the OJIP transients (Duarte et al. 2017). The photochemical stress index (PSI) in that study was proposed as a reliable and sensitive index of the developmental stage of seagrass beds and their growth capacity in endangered environments. Moreover, the importance of the IBR-based photochemical indices in detecting abiotic stresses on photosynthetic organisms has been further emphasized by Stirbet et al. (2018).

The present study aimed to investigate the sensitivity of photochemistry in terms of OJIP transients concerning either leaf dehydration degree under a laboratory protocol or to leaf dehydration duration and recovery under a field protocol. Various native Mediterranean species belonging to different growth forms were studied, such as evergreen sclerophylls, semi-deciduous, deciduous, and winter or summer annuals. More specifically, we tried to: (1) gain more insight into the effects of dehydration on each sub-step of energy flow through photosystems and reveal any differences between species or plant growth forms, (2) investigate if the species or the growth forms share similar patterns of recovery from dehydration, and (3) rank the drought tolerance of the species based on a new drought photochemical index which integrates several parameters of the JIP-test.

\section{Materials and methods}

Plant material: Twelve common Mediterranean species were selected for leaf rapid dehydration experiments (laboratory experiments), including the perennial sclerophylls Arbutus unedo L., Ceratonia siliqua L., Laurus nobilis L., Nerium oleander L., Olea europaea L., and Pistacia lentiscus L., the semi-deciduous Cistus creticus L., Phlomis fruticosa L., and Salvia officinalis L., the summer annual Capparis spinosa L., the winter annual Malva sylvestris L., and the deciduous Cercis siliquastrum L. (Table 1S, supplement). Leaves from individuals of the above-described species were collected from natural populations growing in the country area surrounding the University campus $\left(38.2^{\circ} \mathrm{N}, 21.5^{\circ} \mathrm{E}\right)$. For the drought stress and recovery experiment (slowly imposed dehydration), potted plants under natural environmental conditions were used. Two-year-old individuals of $A$. unedo, C. siliqua, L. nobilis, $N$. oleander, C. creticus, P. fruticosa, and S. officinalis (Table 1S), were obtained from local forest nurseries and transplanted into plastic pots containing a mixture of commercial peat soil and soil collected from the surrounding natural habitat. Potted plants were placed in a protected area of the University campus. The drought stress and recovery experiments were conducted during May, June, and July, including an acclimation period of two months. 
Rapid dehydration experimental protocol: Thirty leaves from each species were selected, according to specific criteria including maturity (Chondrogiannis and Grammatikopoulos 2016), exposure to full sunlight (southern exposure), and a high value of maximum quantum yield of primary photochemistry $\left(\mathrm{F}_{\mathrm{v}} / \mathrm{F}_{\mathrm{m}}=\right.$ $0.800-0.850) . \mathrm{F}_{\mathrm{v}} / \mathrm{F}_{\mathrm{m}}$ was recorded in situ with a portable fluorimeter after $60 \mathrm{~min}$ of dark adaptation. Leaf discs of $1 \mathrm{~cm}$ in diameter, were punched from the selected leaves, transferred within small, sealed plastic bags to the lab, and placed in Petri dishes floating on distilled water for $24 \mathrm{~h}$ in order to become fully turgid, and then turgid mass was measured. Consequently, the leaf discs were placed on filter paper and were progressively dehydrated under laboratory conditions $\left(\mathrm{T}=23-25^{\circ} \mathrm{C}, \mathrm{RH}=40-50 \%\right)$. At regular intervals $(30-60 \mathrm{~min})$, the fresh mass of discs and corresponding $\mathrm{Chl} a$ fluorescence transients were measured, until leaf discs were almost desiccated. Five extra leaf discs, serving as controls, were simultaneously measured at the same intervals but floated each time back on distilled water to retain their initial turgidity. At the end of the experiment, all discs were put in $80^{\circ} \mathrm{C}$ for $24 \mathrm{~h}$, and dry mass was measured. RWC was calculated as described below.

Slow dehydration and recovery experimental protocol: Potted plants of four evergreen sclerophylls and three semi-deciduous species as mentioned above (Table 1S) were selected for the drought stress and recovery measurements. Twenty individuals from each species were randomly arranged into two groups. One group (treatment) was subjected to water stress and recovery and the other one served as control. Water stress applied by withholding water for $15 \mathrm{~d}$. The water stress period was followed by $7 \mathrm{~d}$ of rewatering. Twenty leaves from each group were selected and labeled. The selection was based on their maturity (Chondrogiannis and Grammatikopoulos 2016) and $F_{v} / F_{m}$ values measured before the commencement of the experiment. Both water status and $\mathrm{Chl} a$ fluorescence induction were estimated through RWC measurement and fluorescence kinetics analysis, respectively. RWC was calculated as an average of five measurements, in leaves randomly selected from each group. For Chl $a$ fluorescence recording, predawn measurements were performed on the selected (labeled) leaves. Measurements were conducted at the onset of the experiment, 7 (one week), 12, and 15 (two weeks) d after water withholding, and 1 and $7 \mathrm{~d}$ after rewatering.

Relative water content (RWC) was measured with the leaf disc floating method according to Turner (1981) using the equation $\mathrm{RWC}=(\mathrm{FM}-\mathrm{DM}) \times 100 /(\mathrm{TM}-\mathrm{DM})$, where FM is fresh mass, DM is dry mass and TM is turgid mass. In both experiments, leaf discs were punched from leaves. Discs were floating on distilled water in covered Petri dishes for $24 \mathrm{~h}$, an appropriate time according to preliminary trials and previous work (Petsas and Grammatikopoulos 2009, Chondrogiannis and Grammatikopoulos 2016) to become fully turgid, and TM was measured. During laboratory, rapid dehydration experiments, discs were progressively dehydrated, and FM was recorded at regular intervals. At the end of the experiment, discs were ovendried at $80^{\circ} \mathrm{C}$, for about $24 \mathrm{~h}$ and $\mathrm{DM}$ was obtained. To quantify the degree of dehydration during the slow dehydration experiment, RWC was estimated at regular intervals during both the water stress and the recovery phase.

Chl fluorescence parameters and JIP-test: Chl fluorescence transients (OJIP curves) were recorded by HandyPEA (Hansatech Instruments Ltd., King's Lynn Norfolk, UK). All measurements were conducted on mature leaves or leaf discs punched from them, after dark adaptation for at least $60 \mathrm{~min}$. A bank of three red LEDs (peak at $650 \mathrm{~nm}$ ) providing 3,000 $\mu \mathrm{mol}$ (photon) $\mathrm{m}^{-2} \mathrm{~s}^{-1}$ was used for excitation. Fluorescence was recorded from $10 \mu \mathrm{s}$ to $2 \mathrm{~s}$ with intervals of $10 \mu \mathrm{s}, 100 \mu \mathrm{s}, 1 \mathrm{~ms}$, $10 \mathrm{~ms}$, and $100 \mathrm{~ms}$ between the readings, for periods of $10-300 \mu \mathrm{s}, 0.3-3 \mathrm{~ms}, 3-30 \mathrm{~ms}, 30-300 \mathrm{~ms}$, and $0.3-2 \mathrm{~s}$, respectively. Cardinal points used for further calculation of biophysical parameters were the following: maximal fluorescence intensity $\left(\mathrm{F}_{\mathrm{m}}\right.$, when all RCs are closed), minimum fluorescence intensity $\left(\mathrm{F}_{0}\right.$, when all $\mathrm{RCs}$ are open), and fluorescence intensity at 2 and $30 \mathrm{~ms}$, at the $\mathrm{J}$ and I steps, respectively $\left(\mathrm{F}_{\mathrm{J}}\right.$ and $\left.\mathrm{F}_{\mathrm{I}}\right)$, and at $300 \mu \mathrm{s}\left(\mathrm{F}_{300 \mu \mathrm{s}}\right)$. Relative variable fluorescence at $\mathrm{J}\left[\mathrm{V}_{\mathrm{J}}=\left(\mathrm{F}_{\mathrm{J}}-\mathrm{F}_{0}\right) /\left(\mathrm{F}_{\mathrm{m}}-\mathrm{F}_{0}\right)\right]$ and $\mathrm{I}\left[\mathrm{V}_{\mathrm{I}}=\left(\mathrm{F}_{\mathrm{I}}-\mathrm{F}_{0}\right) /\left(\mathrm{F}_{\mathrm{m}}-\mathrm{F}_{0}\right)\right]$ steps, and at $300 \mu \mathrm{s}$ $\left[\mathrm{V}_{\mathrm{K}}=\left(\mathrm{F}_{\mathrm{K}}-\mathrm{F}_{0}\right) /\left(\mathrm{F}_{\mathrm{m}}-\mathrm{F}_{0}\right)\right]$ was also used. Fluorescence data were then transformed in a logarithmic time scale and the derived polyphasic curve was analyzed according to JIP-test (Strasser et al. 2004) as extended to analyze events around PSI (Oukarroum et al. 2009, Stirbet and Govindjee 2011, Ceppi et al. 2012). The parameters derived from the JIP-test are based on the original energy flux theory (Strasser et al. 2004, Stirbet et al. 2018). Despite the main assumption that the shape of OJIP fluorescence rise reflects changes in redox states of the donor and acceptor side of PSII, other mechanisms may also contribute to the stepwise polyphasic rise. Thus, mechanisms, such as trans-thylakoid electric voltage, electron transport through the inactive branch in PSII, and recombinations between PSII electron acceptors and donors, should be also taken into account in order to explain the OJIP shape modifications (Lazár 2006). Calculations and descriptions of used parameters are as following: $\varphi \mathrm{P}_{0}=\mathrm{TR}_{0} / \mathrm{ABS}=\mathrm{F}_{\mathrm{m}}-\mathrm{F}_{0} / \mathrm{F}_{\mathrm{m}}$, maximum quantum yield of primary PSII photochemistry; $\psi \mathrm{E}_{0}=$ $\mathrm{ET}_{0} / \mathrm{TR}_{0}=1-\mathrm{V}_{\mathrm{J}}$, efficiency/probability with which a PSII trapped electron is transferred from $\mathrm{Q}_{\mathrm{A}}$ to $\mathrm{Q}_{\mathrm{B}}$; $\varphi \mathrm{E}_{0}=\mathrm{ET}_{0} / \mathrm{ABS}=1-\mathrm{F}_{\mathrm{J}} / \mathrm{F}_{\mathrm{m}}=\varphi \mathrm{P}_{0} \times \psi \mathrm{E}_{0}$, quantum yield of the electron transport flux from $\mathrm{Q}_{\mathrm{A}}$ to $\mathrm{Q}_{\mathrm{B}} ; \delta \mathrm{R}_{0}=$ $\mathrm{RE}_{0} / \mathrm{ET}_{0}=\left(1-\mathrm{V}_{\mathrm{I}}\right) /\left(1-\mathrm{V}_{\mathrm{J}}\right)$, efficiency/probability with which an electron from $\mathrm{Q}_{\mathrm{B}}$ is transferred until PSI acceptors; $\varphi \mathrm{R}_{0}=\mathrm{RE}_{0} / \mathrm{ABS}=1-\mathrm{F}_{\mathrm{I}} / \mathrm{F}_{\mathrm{m}}=\varphi \mathrm{P}_{0} \times \psi \mathrm{E}_{0} \times \delta \mathrm{R}_{0}$, quantum yield for reduction of end electron acceptors at the PSI acceptor side; $\mathrm{ABS} / \mathrm{RC}=\left(\mathrm{M}_{0} / \mathrm{V}_{\mathrm{J}}\right) \times\left(1 / \varphi \mathrm{P}_{0}\right)$, absorbed photon flux per reaction center; $\mathrm{TR}_{0} / \mathrm{RC}=\mathrm{M}_{0} / \mathrm{V}_{\mathrm{J}}$, trapped excitation flux (leading to $\mathrm{Q}_{\mathrm{A}}$ reduction) per reaction center; $\mathrm{ET}_{0} / \mathrm{RC}=\left(\mathrm{M}_{0} / \mathrm{V}_{\mathrm{J}}\right) \times\left(1-\mathrm{V}_{\mathrm{J}}\right)$, electron transport flux (further than $\mathrm{Q}_{\mathrm{A}}$ ) per reaction center; 
$\mathrm{DI}_{0} / \mathrm{RC}=\left(\mathrm{ABS} / \mathrm{RC}-\mathrm{TR}_{0} / \mathrm{RC}\right)$, dissipated energy flux per reaction center; $1-V_{I}=\left(F_{m}-F_{I}\right) /\left(F_{m}-F_{0}\right)$, a measure of relative amplitude of the IP phase in OJIP transient, related to the size of the pools of final PSI electron acceptors; $\mathrm{V}_{\mathrm{K}} / \mathrm{V}_{\mathrm{J}}=\left(\mathrm{F}_{300 \mu \mathrm{s}}-\mathrm{F}_{0}\right) /\left(\mathrm{F}_{\mathrm{J}}-\mathrm{F}_{0}\right)$, a measure of the relative amplitude of $\mathrm{K}$-band, related to oxygen evolving complex inactivation; $\mathrm{PI}_{\mathrm{ABS}}=(\mathrm{RC} / \mathrm{ABS}) \times \varphi \mathrm{P}_{0} /\left(1-\varphi \mathrm{P}_{0}\right) \times$ $\psi \mathrm{E}_{0} /\left(1-\psi \mathrm{E}_{0}\right)$, potential for energy conservation from exciton to the reduction of $\mathrm{Q}_{\mathrm{B}} ; \mathrm{PI}_{\text {total }}=\mathrm{PI}_{\mathrm{ABS}} \times \delta \mathrm{R}_{0} /(1-$ $\delta R_{0}$ ), potential for energy conservation from exciton to the reduction of PSI end acceptors.

Drought factor index (DFI): To rank the relative droughtinduced reduction of photosynthetic performance of evergreen sclerophylls and semi-deciduous species, we modified the drought factor index (DFI) as introduced by Oukarroum et al. (2007) by the integrated biomarker response (IBR) analysis as introduced by Beliaeff and Burgeot (2002), Broeg and Lehtonen (2006), and Ferreira et al. (2015) and specified regarding Chl fluorescence parameters by Duarte et al. (2017) and Stirbet et al. (2018). DFI was calculated as DFI $=\log \mathrm{A}+2 \log \mathrm{B}$, where according to Oukarroum et al. (2007) A is the relative performance index measured at the end of the first week of drought and B is the relative performance index measured at the end of the second week of drought stress. The formula emphasizes the importance of a longerterm tolerance, giving twice the relative PI after two weeks of drought stress compared to the relative PI after one week of drought stress. Our modification includes the production of a new photochemical drought index (PDI), that was calculated according to the integrated biomarker response (IBR) analysis (Duarte et al. 2017, Stirbet et al. 2018, Tseliou et al. 2021). The new PDI replaced the performance index in the DFI formula. The PDI integrates the effect of drought on eleven of the Chl fluorescence parameters calculated from the JIP-test in comparison with the performance index which combines three parameters. The calculation procedure for PDI includes seven steps which are described in detail in the Appendix 1.

Statistical analyses: The statistical analysis was conducted with the software package SPSS v.21 (IBM SPSS). Significant differences between treatment means for RWC and $\mathrm{PI}_{\text {total }}$ in the in vivo experiments were determined by independent samples $t$-test. The normal distribution of the corresponding data was previously checked through the Kolmogorov-Smirnov test, as Chl fluorescence data often are not normally distributed (Lazár and Nauš 1998).

\section{Results}

Rapid dehydration (laboratory experiment): To observe rapid, direct effects of dehydration degree on photosynthetic apparatus of twelve Mediterranean species belonging to various growth forms, the JIP-test was applied to leaf discs under stable conditions $\left(\mathrm{T}=23-25^{\circ} \mathrm{C}, \mathrm{RH}=40\right.$ $50 \%$ ) and in the absence of light. The RWC values ranged between $100 \%$ (commencement of the measurements after water saturation of discs) and 5\% (severe dehydration). The duration of the dehydration process was fast but varied among species and lasted 8-10 h in evergreen sclerophylls and 5-7 $\mathrm{h}$ for the rest of the species.

In Fig. 1, representative prompt fluorescence transients from one species (C. creticus) derived at different RWC are shown, for the fast dehydration (Fig. 1A,C,E,G) against slow dehydration (Fig. $1 B, D, F, H$ ). For clarity reasons, averaged curves corresponding to seven levels of hydration (5-90\% RWC) for rapid dehydration and five dates of slow dehydration and recovery are presented. The shape of the OJIP transients changed through the progressive reduction of RWC as depicted both in original transients (Fig. 1 $A, B$ ) and double normalized transients between $\mathrm{O}$ and $\mathrm{P}$ (Fig. 1C,D). Changes of the IP phase with progressive dehydration or/and recovery were emphasized when transients were normalized between $50 \mu \mathrm{s}$ and $2 \mathrm{~ms}\left(\mathrm{~V}_{\mathrm{OJ}}\right)$ (Fig. $\left.1 E, F\right)$. To elucidate the existence of a $\mathrm{K}$-band in the OJ phase, the kinetic difference $\left(\Delta \mathrm{V}_{\mathrm{OJ}}\right)$ is shown in Fig. $1 G, H$. The $\mathrm{K}$-band was more pronounced at low RWC values $(<50 \%)$ during rapid dehydration (Fig. $1 G$ ), while it was insignificant during slow dehydration and recovery (Fig. 1H). L-band did not appear for any species as a difference of the relative variable fluorescence of $\mathrm{O}-\mathrm{K}$ normalized curves during dehydration (data not shown).

The relative amplitude of the IP phase was quantified for all the species by JIP-test parameter $1-\mathrm{V}_{\mathrm{I}}=\left(\mathrm{F}_{\mathrm{m}}-\mathrm{F}_{\mathrm{I}}\right)$ / $\left(\mathrm{F}_{\mathrm{m}}-\mathrm{F}_{0}\right)$ and the relative magnitude of $\mathrm{V}_{\mathrm{K}}$ to $\mathrm{V}_{\mathrm{J}}$ was quantified by $V_{K} / V_{J}$ (Fig. 2). The $1-V_{I}$ value, which reflects the relative size of the pools of final PSI electron acceptors, was reduced with progressive dehydration. This reduction was gradual down to 5\% RWC for the evergreen sclerophylls, the summer annual C. spinosa, and the deciduous $C$. siliquastrum. In semi-deciduous species, the reduction was completed at around $20 \%$, while in the winter annual $M$. sylvestris, the reduction started at RWC $20 \%$ (Fig. 2A). The appearance of the K-band, which indicates partial inhibition of $\mathrm{OEC}$, was marginal in all species (Fig. 2B).

Dehydration-induced changes in parameters derived from the JIP-test are illustrated as a function of RWC in Fig. 3 (representative curves from one species, C. creticus). Trapped energy flux $\left(\mathrm{TR}_{0} / \mathrm{RC}\right)$ and electron transport flux $\left(\mathrm{ET}_{0} / \mathrm{RC}\right)$ per $\mathrm{RC}$ showed an almost linear dependence with RWC, ranging between 20 and $90 \%$, but with rather small slopes (Fig. 3A). Absorption flux per RC (ABS/RC) remained almost constant for the same RWC range (Fig. 3A). The probability that a trapped exciton moves an electron beyond $\mathrm{Q}_{\mathrm{A}}^{-}\left(\psi \mathrm{E}_{0}\right)$ was stable during dehydration, while the probability that an electron can move up to the PSI end electron acceptors $\left(\delta R_{0}\right)$ decreased linearly with RWC reduction (Fig. $3 B$ ). The quantum yield of primary photochemical reaction of PSII $\left(\varphi \mathrm{P}_{0}\right)$ remained constant until $20 \%$ RWC, followed by a sharp reduction. The trends of $\psi \mathrm{E}_{0}$ and $\delta \mathrm{R}_{0}$ affected the behavior of quantum yields of electron transport flux from $\mathrm{Q}_{\mathrm{A}}$ to $\mathrm{Q}_{\mathrm{B}}\left(\varphi \mathrm{E}_{0}\right)$ and of electron transport until the PSI end electron acceptors $\left(\varphi R_{0}\right)$ but differently (Fig. 3C). $\varphi \mathrm{E}_{0}$ was almost constant until $40 \%$ 

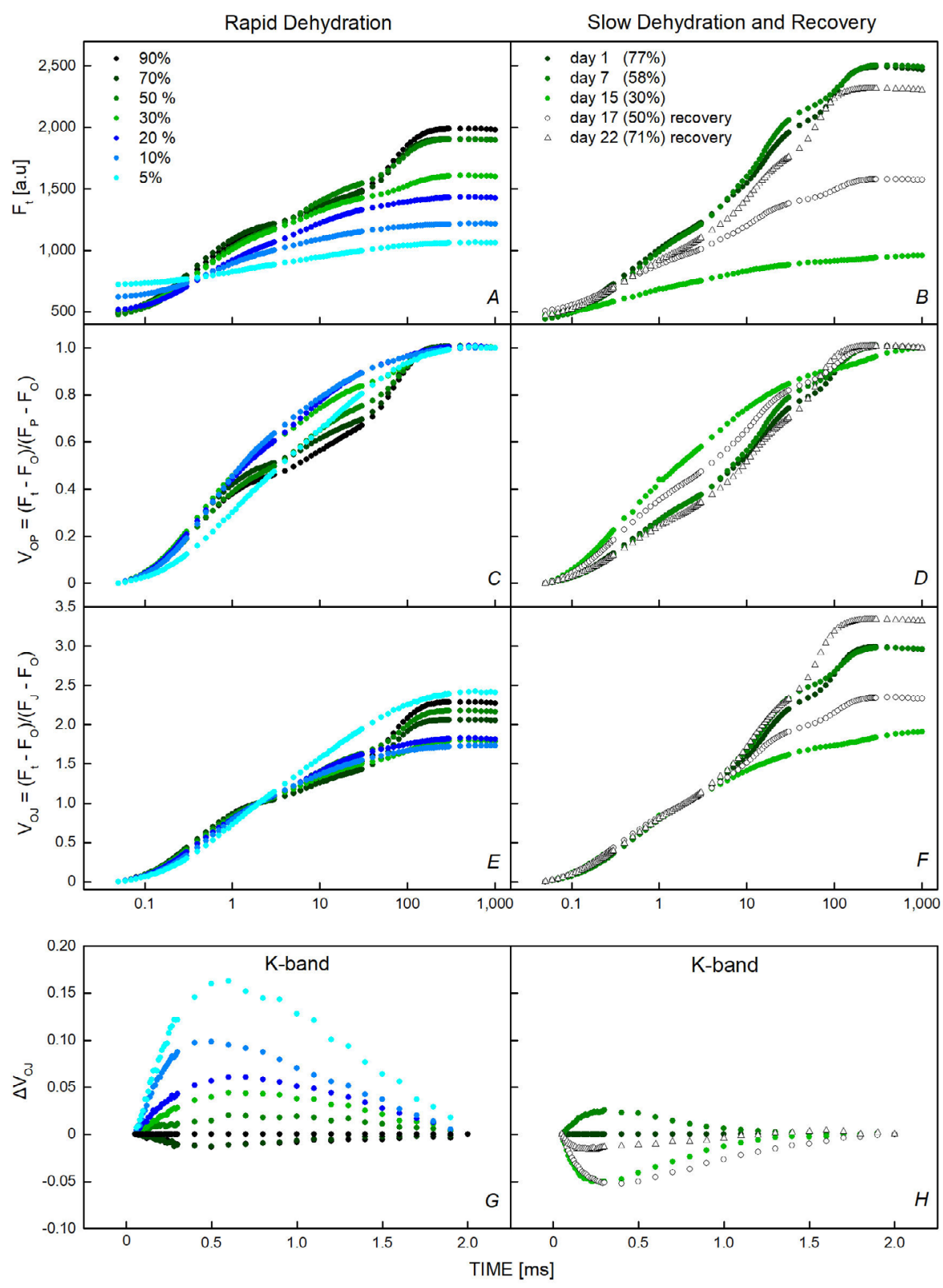

Fig. 1. OJIP Chl $a$ fluorescence transients (log time scale), recorded in dark-adapted leaf discs (rapid dehydration experiment, left panels) and in vivo, in leaves (slow dehydration and recovery experiment, right panels) of Cistus creticus. $(A, B)$ Raw transients exhibiting fluorescence intensity $\left(\mathrm{F}_{\mathrm{t}}\right)$ recorded between $10 \mu \mathrm{s}$ and $1 \mathrm{~s}$ (arbitrary units). $(C, D)$ Double normalized transients between $\mathrm{O}$ and $\mathrm{P}$ points: $\mathrm{V}_{\mathrm{OP}}=\left(\mathrm{F}_{\mathrm{t}}-\mathrm{F}_{0}\right) /\left(\mathrm{F}_{\mathrm{P}}-\mathrm{F}_{0}\right) .(E, F)$. Double normalized transients between $\mathrm{O}$ and $\mathrm{J}$ points: $\mathrm{V}_{\mathrm{OJ}}=\left(\mathrm{F}_{\mathrm{t}}-\mathrm{F}_{0}\right) /\left(\mathrm{F}_{\mathrm{J}}-\mathrm{F}_{0}\right)$. $(G, H) \Delta \mathrm{V}$ curves obtained by subtraction of the original fluorescence transients, normalized between $\mathrm{O}$ and $\mathrm{J}$ points. Differences of the relative variable fluorescence of O-J normalized curves between the different RWC and RWC $=90 \%\left[\Delta \mathrm{V}_{\mathrm{OJ}}=\mathrm{V}_{\mathrm{RWC}}-\mathrm{V}_{\mathrm{RWC} 90 \%},(G)\right]$, and between the $1^{\text {st }} \mathrm{d}$ and the other days $\left[\Delta \mathrm{V}_{\mathrm{OJ}}=\mathrm{V}_{\text {day }}-\mathrm{V}_{\text {dayl }},(H)\right]$. Values are means, $n=10$.

RWC, followed by a gradual, nonlinear, reduction with water loss between 40 and $5 \%$, whilst $\varphi \mathrm{R}_{0}$ decreased linearly as a function of RWC and the magnitude of change (slope of linear regression) was relatively high. Subsequently, performance indexes $\mathrm{PI}_{\mathrm{ABS}}$ and $\mathrm{PI}_{\text {total }}$, which are calculated as the product of three and four independent components respectively (see 'Materials and methods'), showed a linear correlation with RWC, respectively (Fig. $3 D$ ). Values of control samples remained almost stable through the measurement periods (data not shown).

The nature of correlations between the above described JIP-test parameters and the leaf RWC was almost the same for all the examined species. However, significant differences between species appeared, regarding the RWC range for which a parameter remained constant, while, for those parameters that exhibited a linear decrease with water loss, differences between species were found in the 


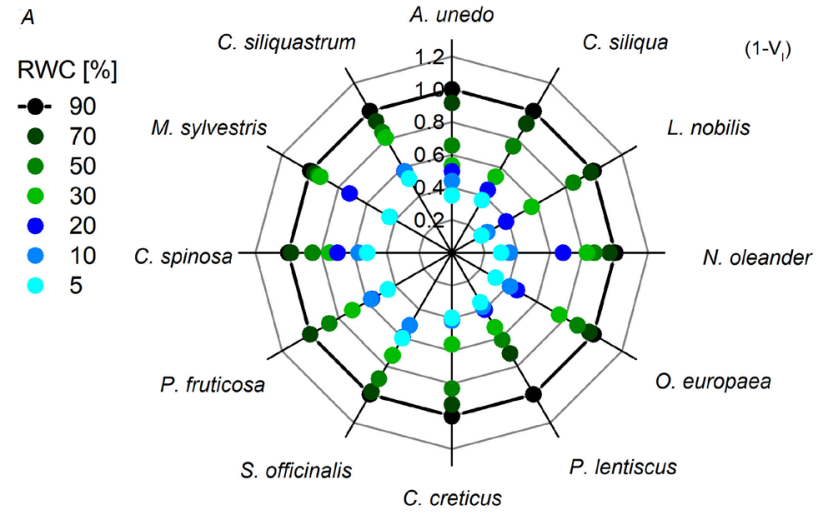

$B$

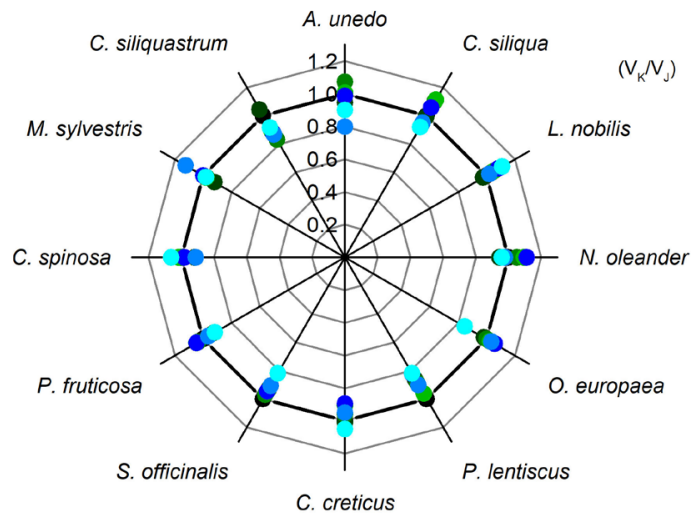

Fig. 2. Radar plots depicting values of $1-\mathrm{V}_{\mathrm{I}}(A)$ and $\mathrm{V}_{\mathrm{K}} / \mathrm{V}_{\mathrm{J}}(B)$ at different RWC in Arbutus unedo, Ceratonia siliqua, Laurus nobilis, Nerium oleander, Olea europaea, Pistacia lentiscus, Cistus creticus, Phlomis fruticosa, Salvia officinalis, Capparis spinosa, Malva sylvestris, and Cercis siliquastrum normalized to the initial values of RWC (90\%). Values are means, $n=10$.

coefficient of determination of the linear regression $\left(R^{2}\right.$; Table 1). The specific energy fluxes (per RC), and $\varphi \mathrm{P}_{0}$ were not affected until severe desiccation (5-20\% RWC). However, $\mathrm{ET}_{0} / \mathrm{RC}$ was affected at higher water content and this trend was more pronounced in evergreen sclerophylls. In two of them, $N$. oleander and P. lentiscus, the sensitivity of $\mathrm{ET}_{0} / \mathrm{RC}$ appeared at RWC $80 \%$. Reduction of $\varphi \mathrm{E}_{0}$ appeared at even higher RWC (50-90\%) in evergreens except for $A$. unedo. The corresponding range for the semi-deciduous species was $20-40 \%$ and for the deciduous and annual species between $10-25 \%$. $\varphi \mathrm{R}_{0}, \psi \mathrm{E}_{0}$, $\delta \mathrm{R}_{0}, \mathrm{PI}_{\mathrm{ABS}}$, and $\mathrm{PI}_{\text {total }}$ decreased linearly with dehydration in all the species. The coefficient of determination of the linear regression $\left(R^{2}\right)$ indicated best fit in the order of $\varphi \mathrm{R}_{0}(0.63-0.97), \mathrm{PI}_{\text {total }}(0.53-0.93), \delta \mathrm{R}_{0}(0.49-0.96), \psi \mathrm{E}_{0}$ (0.27-0.80), and $\mathrm{PI}_{\mathrm{ABS}}(0.28-0.74) . \psi \mathrm{E}_{0}$ in $C$. creticus was constant while a linear decrease of $\varphi \mathrm{R}_{0}, \delta \mathrm{R}_{0}$, and $\mathrm{PI}_{\text {total }}$ in C. siliquastrum was marginal and no correlation appeared regarding $\psi \mathrm{E}_{0}$ and $\mathrm{PI}_{\mathrm{ABs}}$.

Slow dehydration under semi-natural conditions (field experiment): Potted individuals of four evergreen and three semi-deciduous species were tested for the sensitivity of photosynthetic apparatus to drought stress (two weeks) and recovery (one week). RWC and $\mathrm{PI}_{\text {total }}$ fluctuations during water withholding and rewatering period, as well as corresponding values of controls, are depicted in Fig. 4. After two weeks of water withholding, RWC dropped significantly, to $40-60 \%$ in evergreens (Fig. $4 A, C, E, G$ ) and $30-50 \%$ in semi-deciduous species (Fig. $4 B, D, F$ ). However, during the first week, only the semi-deciduous species experienced water stress as RWC dropped to $60-70 \%$. Corresponding values of the control individuals were almost constant. Rewatering of plants during the third week of the experiment allowed full rehydration of evergreens (80-90\% RWC), already achieved in $24 \mathrm{~h}$. Rehydration of semi-deciduous species was progressive and resulted in full recovery only in P. fruticosa (Fig. 4D). $\mathrm{PI}_{\text {total }}$ followed the trends of RWC in evergreens without significant changes during the first week (Fig. 4A,C,E,G). At the end of the water stress period, $\mathrm{PI}_{\text {total }}$ dropped to a minimum and progressively increased during the recovery period but did not reach the control value with the end of the experiment. On the other hand, in semi-deciduous species, $\mathrm{PI}_{\text {total }}$ was influenced only when RWC was reduced to $40 \%$ in C. creticus and P. fruticosa (Fig. $4 B, D$ ) and $50 \%$ in $S$. officinalis (Fig. $4 F$ ), but fully recovered after one week.

An appearance of the L-band, which has been related to connectivity and excitation energy transfer between PSII units (Strasser and Stirbet 1998), was obvious for all the species (Fig. 5) except $S$. officinalis (Fig. 5F) after water-stress treatment. However, the L-band disappeared only in $N$. oleander after one week of rewatering (Fig. 5B).

According to the IBR methodology, radar plots were produced, including the scores of selected $\mathrm{Chl}$ fluorescence parameters, regarding them as distinct biomarkers (Fig. 6). The initial scores of the JIP-test parameters (watered), the scores at the end of the first and the second week of the drought period (water stress), and the scores after one-week rewatering (recovery) are presented as radar plots. More specifically, the deviation of the graphical pattern of water stress treatment from that of the control was similar in all species except $S$. officinalis (Fig. 6F). The water stress pattern includes an increase of specific energy fluxes $\mathrm{ABS} / \mathrm{RC}, \mathrm{TR}_{0} / \mathrm{RC}, \mathrm{DI}_{0} / \mathrm{RC}$ and decrease of quantum yields $\varphi \mathrm{P}_{0}, \varphi \mathrm{E}_{0}, \varphi \mathrm{R}_{0}$, as well as of $\psi \mathrm{E}_{0}$, and $1-V_{\mathrm{I}} . \mathrm{V}_{\mathrm{K}} / \mathrm{V}_{\mathrm{J}}$ increased only in evergreens and $\delta \mathrm{R}_{0}$ decreased only in semi-deciduous species. In S. officinalis, only the parameters related to electron transport round the $\operatorname{PSI}\left(\delta \mathrm{R}_{0}, \varphi \mathrm{R}_{0}, 1-\mathrm{V}_{\mathrm{I}}\right)$ were reduced (Fig. $\left.6 F\right)$. The recovery pattern poses more differences between the species. Almost all the parameters recovered after one-week rewatering in $C$. creticus, $N$. oleander, and $S$. officinalis (Fig. 6B,C,F). In the rest of evergreens and P. fruticosa, the recovery was partial in most of the parameters with yields being more responsive than specific energy fluxes (Fig. $6 A, D, E, G) . \varphi \mathrm{P}_{0}$ was reduced only at the lowest RWC and fully recovered in all species.

Ranking of the drought tolerance of evergreen sclerophylls and semi-deciduous species based on a drought factor index (DFI) is presented in Fig. 7 either calculated 


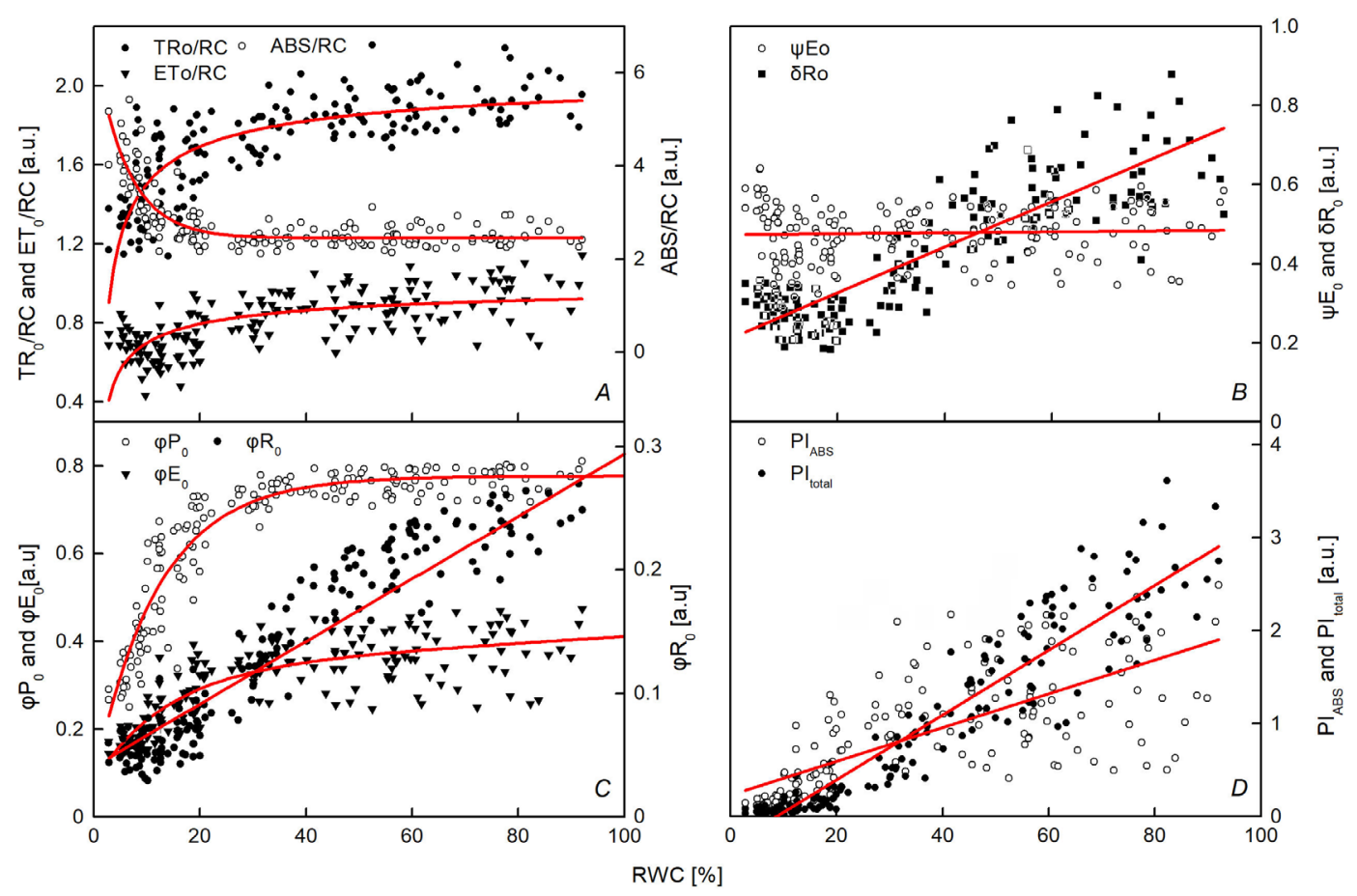

Fig. 3. Representative relationship between RWC and specific energy fluxes per active PSII reaction center $(A)$, efficiencies/ probabilities $(B)$, quantum yields $(C)$ and performance indices $(D)$, for Cistus creticus. Data calculated from 172 induction curves of samples with different water content during the rapid dehydration experiment. The red lines represent the linear $\left(\varphi \mathrm{R}_{0}, \psi \mathrm{E}_{0}, \delta \mathrm{R}_{0}, \mathrm{PI}_{\mathrm{ABS}}\right.$, and $\left.\mathrm{PI}_{\text {total }}\right)$ or the nonlinear $\left(\mathrm{ABS} / \mathrm{RC}, \mathrm{TR}_{0} / \mathrm{RC}, \mathrm{DI}_{0} / \mathrm{RC}, \mathrm{ET}_{0} / \mathrm{RC}, \varphi \mathrm{P}_{0}\right.$, and $\left.\varphi \mathrm{E}_{0}\right)$ regressions of the experimental points.

Table 1. The nature of correlations between the JIP-test parameters and the leaf relative water content (RWC) during rapid leaf dehydration. $\mathrm{ABS} / \mathrm{RC}$ - absorbed photon flux per reaction center of PSII; $\mathrm{DI}_{0} / \mathrm{RC}$ - dissipated energy flux per reaction center of PSII; $\mathrm{ET}_{0} / \mathrm{RC}$ - electron transport flux per reaction center of PSII, $\mathrm{TR}_{0} / \mathrm{RC}$ - trapped excitation flux per reaction center of $\mathrm{PSII} ; \mathrm{PI}_{\mathrm{ABS}}-$ potential for energy conservation from exciton to the reduction of $\mathrm{Q}_{\mathrm{B}} ; \mathrm{PI}_{\text {total }}$ - potential for energy conservation from exciton to the reduction of PSI end acceptors, $\delta \mathrm{R}_{0}$ - efficiency/probability with which an electron fromPQH $\mathrm{P}_{2}$ is transferred to final PSI acceptors, $\varphi \mathrm{E}_{0}$ - quantum yield of the electron transport flux from $\mathrm{Q}_{\mathrm{A}}$ to $\mathrm{PQ}, \varphi \mathrm{P}_{0}$ - maximum quantum yield of primary PSII photochemistry, $\varphi \mathrm{R}_{0}$ - quantum yield of electron transport from $\mathrm{Q}_{\mathrm{A}}^{-}$to final PSI acceptors, $\psi \mathrm{E}_{0}$ - efficiency/probability with which a PSII trapped electron is transferred from $\mathrm{Q}_{\mathrm{A}}$ to $\mathrm{PQ} . R^{2}$ represents the coefficient of determination of the linear regression.

\begin{tabular}{|c|c|c|c|c|c|c|c|c|c|c|c|c|}
\hline \multirow[t]{2}{*}{ Growth form } & \multirow[t]{2}{*}{ Species } & \multicolumn{6}{|c|}{$\begin{array}{l}\text { Nonlinear } \\
\text { minimum RWC value of the linear part of the } \\
\text { correlation }[\%]\end{array}$} & \multicolumn{5}{|c|}{$\begin{array}{l}\text { Linear } \\
R^{2}\end{array}$} \\
\hline & & $\mathrm{ABS} / \mathrm{RC}$ & $\mathrm{TR}_{0} / \mathrm{RC}$ & $\mathrm{DI}_{0} / \mathrm{RC}$ & $\mathrm{ET}_{0} / \mathrm{RC}$ & $\varphi \mathrm{P}_{0}$ & $\varphi \mathrm{E}_{0}$ & $\varphi \mathrm{R}_{0}$ & $\psi \mathrm{E}_{0}$ & $\delta \mathrm{R}_{0}$ & $\mathrm{PI}_{\mathrm{ABS}}$ & $\mathrm{PI}_{\text {total }}$ \\
\hline evergreen & Arbutus unedo & 20 & 20 & 15 & 30 & 20 & 25 & 0,71 & 0.48 & 0.53 & 0.58 & 0.67 \\
\hline \multirow[t]{5}{*}{ sclerophylls } & Ceratonia siliqua & 10 & 10 & 15 & 30 & 20 & 80 & 0.97 & 0.80 & 0.96 & 0.74 & 0.93 \\
\hline & Laurus nobilis & 20 & 10 & 20 & 40 & 20 & 50 & 0.91 & 0.75 & 0.72 & 0.68 & 0.80 \\
\hline & Nerium oleander & 10 & 10 & 10 & 80 & 15 & 80 & 0.63 & 0.44 & 0.49 & 0.25 & 0.54 \\
\hline & Olea europaea & 15 & 10 & 15 & 20 & 15 & 50 & 0.89 & 0.72 & 0.83 & 0.68 & 0.76 \\
\hline & Pistacia lentiscus & 20 & 20 & 20 & 80 & 25 & 90 & 0.78 & 0.70 & 0.58 & 0.66 & 0.70 \\
\hline \multirow[t]{3}{*}{ semi-deciduous } & Cistus creticus & 20 & 25 & 20 & 40 & 35 & 30 & 0.89 & 0.01 & 0.66 & 0.45 & 0.84 \\
\hline & Phlomis fruticosa & 10 & 10 & 20 & 20 & 15 & 20 & 0.92 & 0.74 & 0.74 & 0.61 & 0.81 \\
\hline & Salvia officinalis & 10 & 10 & 10 & 30 & 10 & 20 & 0.75 & 0.27 & 0.49 & 0.28 & 0.53 \\
\hline winter annual & Malva sylvestris & 10 & 10 & 10 & 10 & 10 & 25 & 0.82 & 0.54 & 0.82 & 0.53 & 0.71 \\
\hline summer annual & Capparis spinosa & 10 & 5 & 5 & 30 & 10 & 30 & 0.75 & 0.52 & 0.64 & 0.57 & 0.57 \\
\hline deciduous & Cercis siliquastrum & 5 & 5 & 5 & 5 & 10 & 10 & 0.36 & 0.06 & 0.56 & 0.04 & 0.30 \\
\hline
\end{tabular}




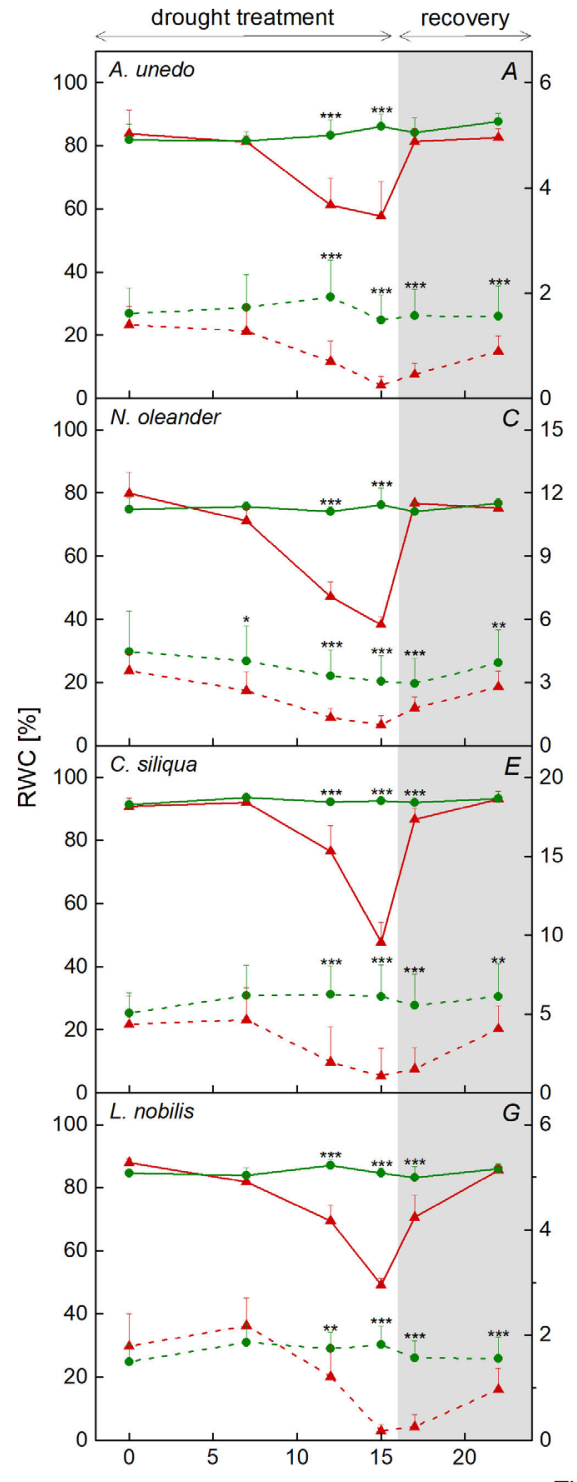

TIME [d]

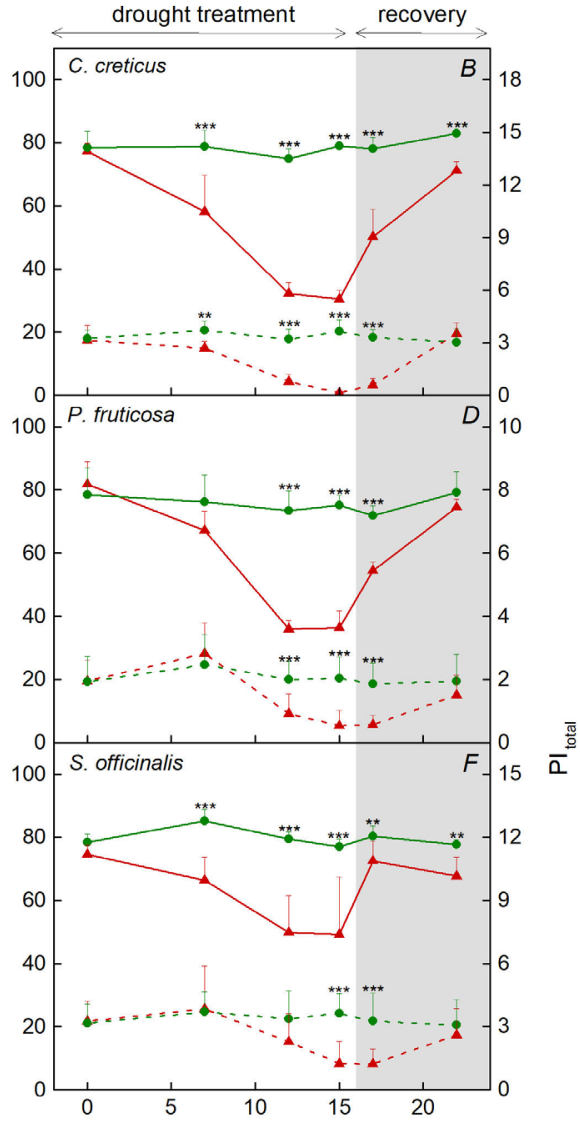

$\longleftarrow$ RWC (water stress)
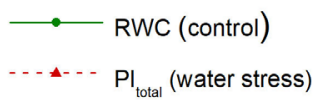

-.... $\mathrm{PI}_{\text {total }}$ (control)

Fig. 4. Variation of $\mathrm{PI}_{\text {total }}$ and RWC during water withholding (white pattern) and rewatering period (grey pattern), in control (green circles) and waterstressed plants (red triangles) of Arbutus unedo $(A)$, Cistus creticus (B), Nerium oleander $(C)$, Phlomis fruticosa $(D)$, Ceratonia siliqua $(E)$, Salvia officinalis $(F)$, and Laurus nobilis $(G)$. Values are means $\pm \mathrm{SD}, n=20$. on $\mathrm{PI}_{\text {total }}$ (Fig. $7 A$ ) or the herein introduced photochemical drought index (PDI) (Fig. 7B). DFI is representing the relative drought-induced reduction of the $\mathrm{PI}_{\text {total }}$ (Oukarroum et al. 2007) during dehydration. Increasingly negative values denote lower drought resistance (Fig. 7A). Thus, $S$. officinalis and $P$. fruticosa showed less negative values and can be characterized as the most droughtresistant species, the evergreens followed in the order of $N$. oleander, C. siliqua, A. unedo, and L. nobilis, while $C$. creticus appeared as the most drought-sensitive species. However, when DFI was based on PDI (Fig. 7B), ranking inside the growth form of evergreen species changed as increasingly higher values denote lower drought resistance. The most resistant species was L. nobilis, followed by $N$. oleander, A. unedo, and $C$. siliqua. The ranking among semi-deciduous species was in the order of $S$. officinalis, P. fruticosa, and C. creticus. It should be noted that the use of PDI did not change the ranking between the two growth forms.

\section{Discussion}

Withdrawal of plant cell water causes reduction of water potential and turgor pressure and increase of osmotic pressure as diluted substances accumulate. These changes can affect the cell and chloroplast membrane integrity and can induce modifications in chloroplast ultrastructure (Lauriano et al. 2000). The question arises, how quickly the structural and functional reorganization of the thylakoids and the photosystems occur and are these modifications common among different species or growth forms of Mediterranean native plants?

Rapid dehydration in the present study reduced RWC in most species by more than $80-90 \%$, while during slow dehydration, the lowest RWC for evergreen sclerophylls ranged between $38-50 \%$ and for semideciduous species between 30-49\%. According to the field, seasonal measurements in the same shrub species, minimal RWC (40-60\%) was recorded in August, with 


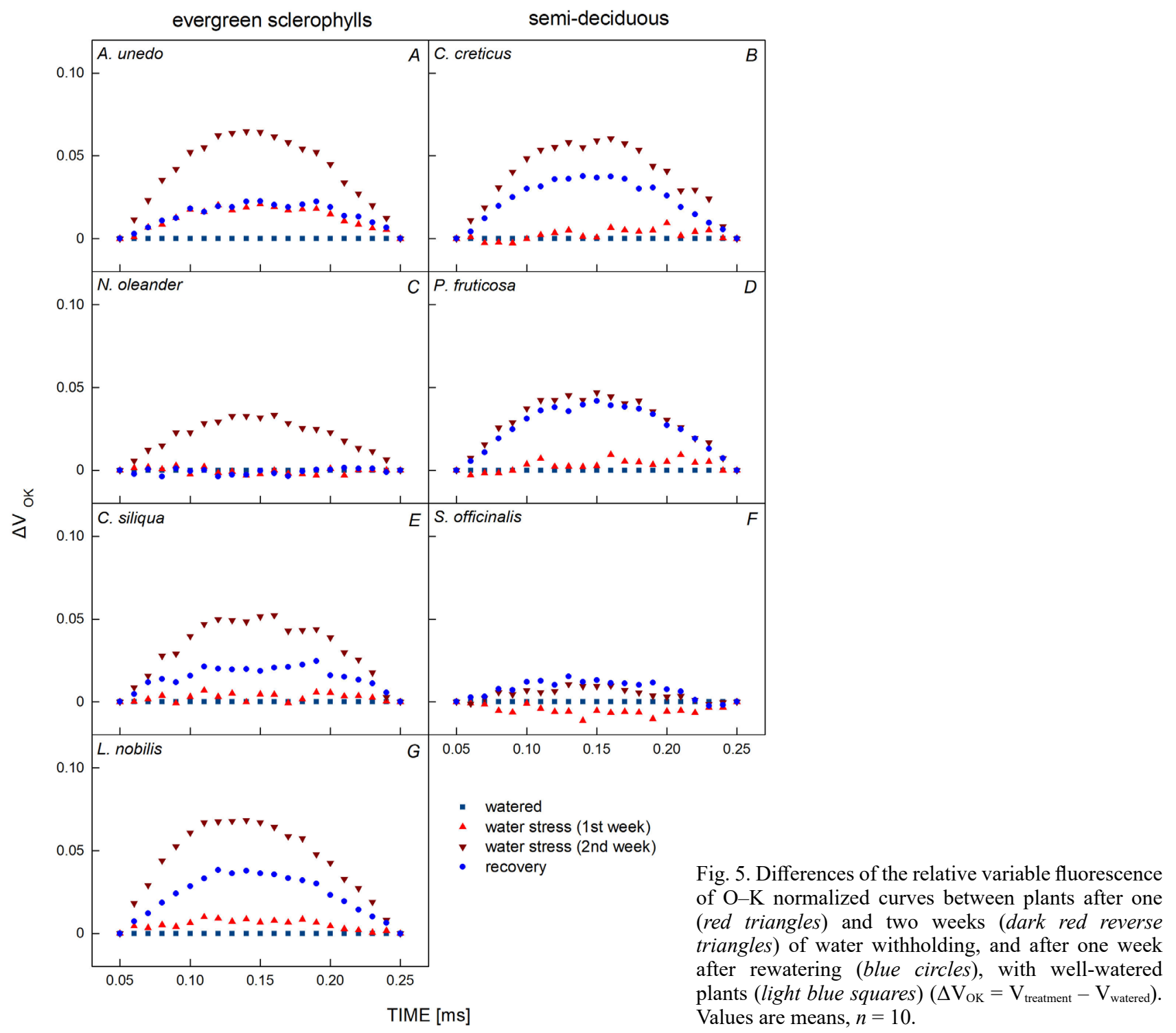

the semi-deciduous $P$. fruticosa exhibiting values around 30\% (Karavatas and Manetas 1999). Additionally, in a recent work (Chondrogiannis and Grammatikopoulos 2021), RWC during summer in juveniles of the evergreen $N$. oleander and the semi-deciduous $P$. fruticosa was also around $30-40 \%$. Therefore, the water stress achieved in our in vivo experiments was representative of the fluctuations under natural environmental conditions.

The shape of the fluorescence transients was significantly different between rapidly and slowly dehydrated samples. The differences were more pronounced when transients were double normalized either in $F_{0}$ and $F_{P}$ or in $\mathrm{F}_{0}$ and $\mathrm{F}_{\mathrm{J}}$, indicating that $\mathrm{OJ}, \mathrm{JI}$, and IP phases were affected in a different way under slow or rapid dehydration. Therefore, biophysical parameters which are related to each phase were expected to differ accordingly (TsimilliMichael 2020). During rapid dehydration, a faster rise of fluorescence at point $\mathrm{P}$, an increase of $\mathrm{F}_{0}$, and a decrease of $\mathrm{F}_{\mathrm{m}}$ were recorded at low RWC, the above being indicative of the $\mathrm{Q}_{\mathrm{A}}^{-}$accumulation (Oukarroum et al. 2009) and OEC inhibition (Lazár 2006, Bednaříková et al. 2020). OEC inhibition occurred in laboratory experiments only at very low RWC (5-20\%), while in a previous study with lichens, water stress acted as a predisposing factor that enhanced the resistance to heat (Oukarroum et al. 2012). In the present study, slow dehydration and co-existed high temperature, led to the disappearance of the K-band. On the other hand, a gradual decrease of the relative amplitude of the IP phase with progressive reduction of leaf water content occurred in almost all species, indicating that PSI reaction centers and electron transport until the PSI final acceptors was affected by increasing water stress (Oukarroum et al. 2009, Ceppi et al. 2012, Živčák et al. 2014). It should be noted that the species of the present study are usually experiencing significant dehydration of more than $50 \%$ already during late spring and early summer and dehydration worsening during mid or late summer (Karavatas and Manetas 1999, Galmés et al. 
A. unedo

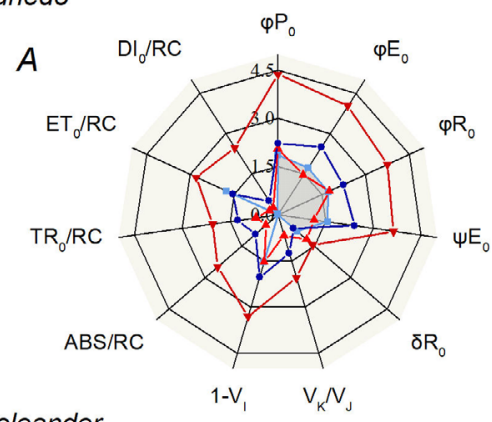

N. oleander
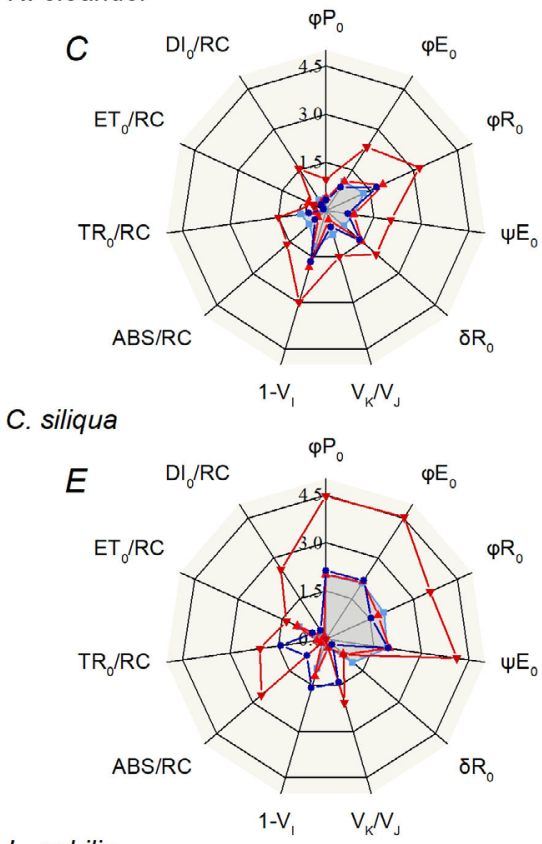

L. nobilis

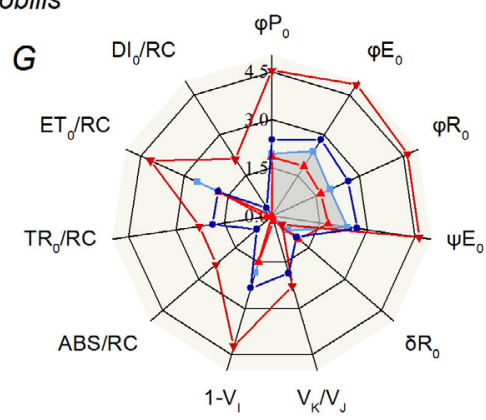

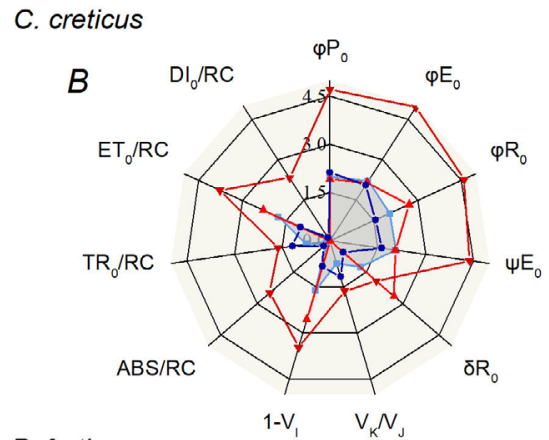

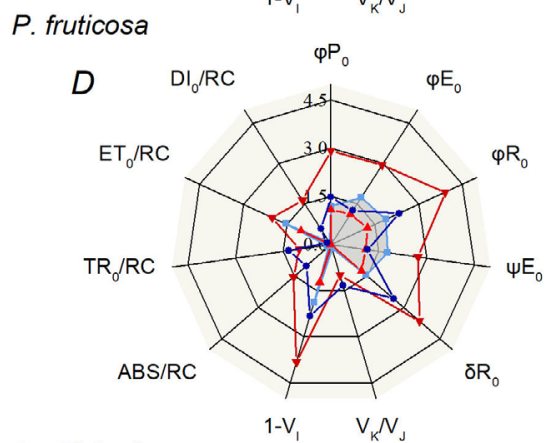

S. officinalis

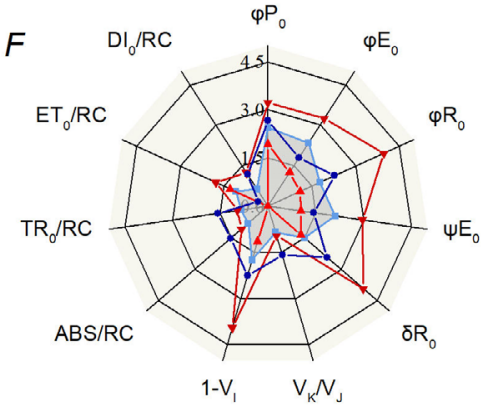

Fig. 6. Radar plots of the scores, calculated by the IBR method, for the selected chlorophyll fluorescence parameters from JIP-test analysis, in well-watered plants (light blue squares), in plants after one (red triangles) and two weeks (dark red reverse triangles) of water withholding, and after one week after rewatering (blue circles). Scores calculated from ten individuals for each species and for each treatment.
2012, Chondrogiannis and Grammatikopoulos 2021). On the contrary, in the winter annual M. sylvestris, which does not confront water stress during its life cycle, the IP phase was affected only under $20 \%$ RWC which is not a realistic value under field conditions.

The transport of electrons through the intersystem and the PSI was significantly affected by water stress as shown by the negative correlation of quantum yields $\varphi \mathrm{E}_{0}, \varphi \mathrm{R}_{0}$, and the probabilities $\psi \mathrm{E}_{0}$ and $\delta \mathrm{R}_{0}$ with the RWC during rapid dehydration. These findings confirm the inhibition of electron flow in dehydrated bean leaves (Goltsev et al.
2012) and barley leaves (Oukarroum et al. 2007). The same parameters were affected during the second week of slow dehydration under field conditions in our study. Therefore, regardless of the fast or slow developed dehydration, the movement of electrons from PSII to $\mathrm{Q}_{\mathrm{A}}$, to $\mathrm{PQ}$, and finally to the final electron receptors of PSI was significantly affected. Photosynthetic performance, expressed by the $\mathrm{PI}_{\mathrm{ABS}}$ and $\mathrm{PI}_{\text {total }}$ parameters, was also significantly reduced, for all species studied both under laboratory conditions and in vivo. The $\mathrm{PI}_{\mathrm{ABS}}$ index is particularly sensitive to drought conditions and has been suggested by many authors as a 


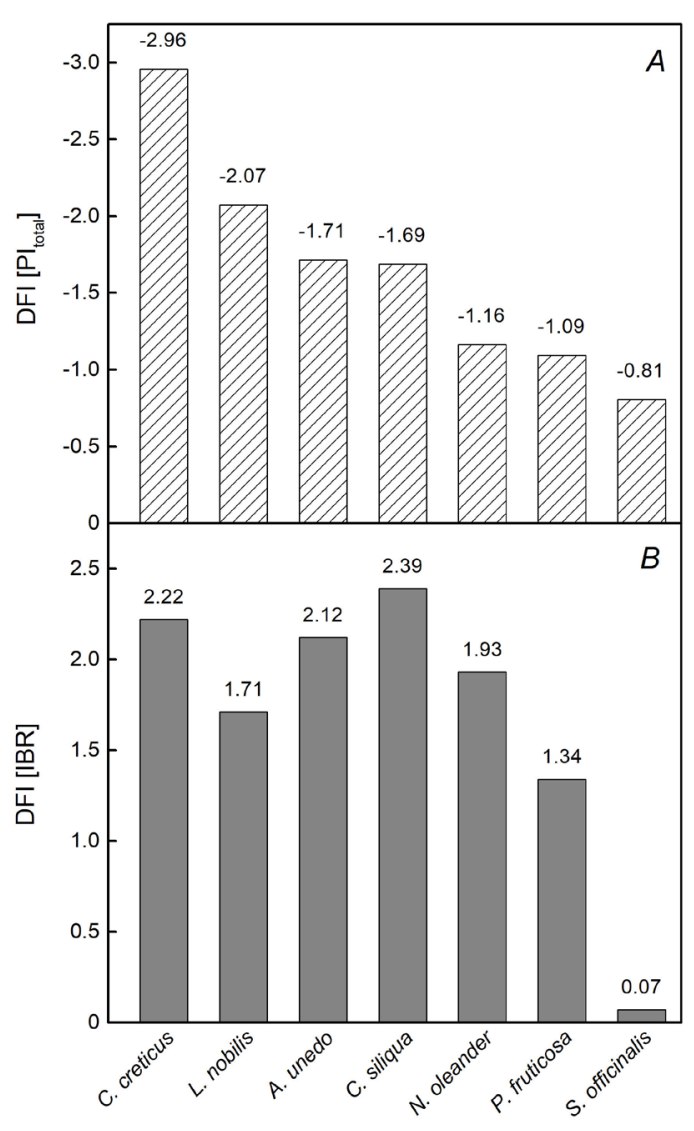

Fig. 7. Values of drought factor index (DFI) based on $\mathrm{PI}_{\text {total }}(A)$ or on photochemical drought index (PDI) (B), for Arbutus unedo, Nerium oleander, Ceratonia siliqua, Laurus nobilis, Cistus creticus, Phlomis fruticosa, and Salvia officinalis plants.

suitable tool for monitoring photosynthetic performance, which in contrast to the $F_{v} / F_{m}$ index, changes even in mild water stress conditions (Oukarroum et al. 2007, Živčák et al. 2008, Goltsev et al. 2012).

Regarding the recovery ability of the photosynthetic function after rehydration of plants, it is known that the effects are usually reversed when the RWC has not declined below $50 \%$, up to which no significant membrane damage and cell integrity has been observed (Kaiser 1987, Dekov et al. 2000, Lauriano et al. 2000, Matos et al. 2002). The reverse of the water stress effects on Chl fluorescence parameters in the present study began on the first day after rehydration, which is consistent with the observation of Flexas et al. (2004), that under mild stress, photosynthesis is rapidly restored in welladapted plants. It should be noted that, during our field experiments, in most species, RWC dropped to very low values (30-58\%), which denotes severe water stress. Therefore, the photosynthetic machinery in these species can be concerned as considerably tolerant to water stress. However, in the evergreen sclerophylls recovery of performance was not complete after one week, while in semi-deciduous species almost all the parameters, except for those related to PSI, completely recovered. In previous work with the semi-deciduous Phlomis fruticosa (Petsas and Grammatikopoulos 2009), reduced electron flow and quantum yields under conditions of extreme water stress completely reversed after rehydration. Additionally, the appearance of an L-band in all the species but $S$. officinalis after two weeks of dehydration denotes destacking and disorganization of the membrane structure of thylakoids and altered connectivity among PSII units (Strasser and Stirbet 1998, Oukarroum et al. 2007, Campos et al. 2014). After one week of rehydration, connectivity of PSII units was fully restored only in $N$. oleander, and partly restored in the rest of the species. When measured in an Antarctic lichen, which is well adapted to dessication/ rehydration cycles, most of the parameters of the JIPtest were affected (Bednaříková et al. 2020). Similar to the present study, the appearance of the K- and L-bands and activation of protective mechanisms $\left(\mathrm{DI}_{0} / \mathrm{RC}\right)$ occurred as a result of low RWC. It is interesting that the increased demand for protective mechanisms found for the lichen under relatively higher temperatures it is also true for the different life forms of Mediterranean drought-adapted shrubs during slow dehydration under field conditions. The recovery pattern as a whole may be attributed to the different adaptations of the two plant growth forms to water stress (Grammatikopoulos et al. 1995, Petsas and Grammatikopoulos 2009, Galmés et al. 2012, Chondrogiannis and Grammatikopoulos 2021). In particular, the recovery efficiency of photosynthesis has been generally referred low in sclerophylls medium in semi-deciduous and high in annual species (Galmés et al. 2007). It seems, therefore, that the ability to quickly recover from water stress in semi-deciduous species is more critical for their energy support than in sclerophylls during the dry period of the year. On the other hand, sclerophylls, which possess morphological and physiological adaptations against the drought of a more permanent character, do not respond quickly to changes of water availability, at the cost of reduced $\mathrm{CO}_{2}$ assimilation, which, however, is offset by the longer lifespan of their leaves. It should be noted that the JIP-test parameters alone do not include many independent pieces of information regarding the underlying physiological mechanisms (Tsimilli-Michael 2020) and should be accompanied by measurements, e.g., of $\mathrm{CO}_{2}$ assimilation rate if a deeper insight into the drought tolerance repertoire of a species is requested (Galmés et al. 2007, Chondrogiannis and Grammatikopoulos 2021). However, the JIP-test has been recognized as a valuable tool for screening abiotic stress impact and plant tolerance in large samples/populations (Stirbet et al. 2018).

Although drought tolerance among evergreen sclerophylls and semi-deciduous shrubs differed only in recovery patterns, species of the same growth form did not share the same tolerance to dehydration. An efficient ranking of species or varieties according to their drought tolerance has been made with the use of the drought factor index DFI (Oukarroum et al. 2007, 2009), allocating the impact of drought on photochemical index (PI) reduction over time. The PI alone is a sensitive index of stress as it takes into consideration three $\left(\mathrm{PI}_{\mathrm{ABS}}\right)$ or four $\left(\mathrm{PI}_{\text {total }}\right)$ steps of the energy flow through the photosystems. In the 
present study, the creation of a new photochemical index (photochemical drought index, PDI), which integrates eleven sensitive parameters from the JIP-test, was used for the DFI estimation. The new ranking revealed changes in the order of evergreens' resistance to dehydration, enlarged the existing differences of drought tolerance between the species placed into the new order, but did not change the general rank between the two growth forms. It seems, therefore, that a more 'detailed' index such as the PDI is useful for discriminating small differences between species, while the traditional photochemical indices are also capable of discriminating large groups like the different plant growth forms.

In conclusion, rapid dehydration affected negatively the photosynthetic performance of all the studied species regardless of the plant growth form. The most pronounced effect was found in parameters related to electron flow up to the PSI acceptor side. The slow development of water stress under natural environmental conditions influenced evergreen sclerophylls and semi-deciduous species in a similar manner, but differently during recovery from dehydration. However, the ranking of drought tolerance of the seven studied species revealed differences when estimated either based on $\mathrm{PI}_{\text {total }}$ or based on the herein created photochemical drought index (PDI) which integrates the effect of dehydration on eleven parameters of the JIP-test.

\section{References}

Bednaříková M., Váczi P., Lazár D., Barták M.: Photosynthetic performance of Antarctic lichen Dermatocarpon polyphyllizum when affected by desiccation and low temperatures. - Photosynth. Res. 145: 159-177, 2020.

Beliaeff B., Burgeot T.: Integrated biomarker response: A useful tool for ecological risk assessment. - Environ. Toxicol. Chem. 21: 1316-1322, 2002.

Broeg K., Lehtonen K.K.: Indices for the assessment of environmental pollution of the Baltic Sea coasts: Integrated assessment of a multi-biomarker approach. - Mar. Pollut. Bull. 53: 508-522, 2006.

Bussotti F.: Assessment of stress conditions in Quercus ilex L. leaves by O-J-I-P chlorophyll $a$ fluorescence analysis. - Plant Biosyst. 138: 101-109, 2004.

Campos H., Trejo C., Peña-Valdivia C.B. et al.: Stomatal and non-stomatal limitations of bell pepper (Capsicum annuum L.) plants under water stress and re-watering: Delayed restoration of photosynthesis during recovery. - Environ. Exp. Bot. 98: 56-64, 2014.

Ceppi M.G., Oukarroum A., Çiçek N. et al.: The IP amplitude of the fluorescence rise OJIP is sensitive to changes in the photosystem I content of leaves: A study on plants exposed to magnesium and sulfate deficiencies, drought stress and salt stress. - Physiol. Plantarum 144: 277-288, 2012.

Chaves M.M., Flexas J., Pinheiro C.: Photosynthesis under drought and salt stress: Regulation mechanisms from whole plant to cell. - Ann. Bot.-London 103: 551-560, 2009.

Chaves M.M., Maroco J.P., Pereira J.S.: Understanding plant responses to drought - from genes to the whole plant. - Funct. Plant Biol. 30: 239-264, 2003.

Chondrogiannis C., Grammatikopoulos G.: Photosynthesis in developing leaf of juveniles and adults of three Mediterranean species with different growth forms. - Photosynth. Res. 130:
427-444, 2016.

Chondrogiannis C., Grammatikopoulos G.: Transition from juvenility to maturity strengthens photosynthesis in sclerophyllous and deciduous but not in semi-deciduous Mediterranean shrubs. - Environ. Exp. Bot. 180: 104265, 2021.

Dekov I., Tsonev T., Yordanov I.: Effects of water stress and high-temperature stress on the structure and activity of photosynthetic apparatus of Zea mays and Helianthus annuus. - Photosynthetica 38: 361-366, 2000.

Duarte B., Pedro S., Marques J.C. et al.: Zostera noltii development probing using chlorophyll $a$ transient analysis (JIP-test) under field conditions: Integrating physiological insights into a photochemical stress index. - Ecol. Indic. 76: 219-229, 2017.

Ferreira N.G.C., Morgado R., Santos M.J.G. et al.: Biomarkers and energy reserves in the isopod Porcellionides pruinosus: The effects of long-term exposure to dimethoate. - Sci. Total Environ. 502: 91-102, 2015.

Flexas J., Barbour M.M., Brendel O. et al.: Mesophyll diffusion conductance to $\mathrm{CO}_{2}$ : An unappreciated central player in photosynthesis. - Plant Sci. 193-194: 70-84, 2012.

Flexas J., Bota J., Cifre J. et al.: Understanding down-regulation of photosynthesis under water stress: future prospects and searching for physiological tools for irrigation management. Ann. Appl. Biol. 144: 273-283, 2004.

Flexas J., Diaz-Espejo A., Gago J. et al:: Photosynthetic limitations in Mediterranean plants: A review. - Environ. Exp. Bot. 103: 12-23, 2014.

Flexas J., Medrano H.: Drought-inhibition of photosynthesis in $\mathrm{C}_{3}$ plants: Stomatal and non-stomatal limitations revisited. Ann. Bot.-London 89: 183-189, 2002.

Galmés J., Flexas J., Medrano H. et al.: Ecophysiology of photosynthesis in semi-arid environments. - In: Flexas J., Loreto F., Medrano H. (ed.): Terrestrial Photosynthesis in a Changing Environment. A Molecular, Physiological and Ecological Approach. Pp. 448-464. Cambridge University Press, Cambridge 2012.

Galmés J., Medrano H., Flexas J.: Photosynthetic limitations in response to water stress and recovery in Mediterranean plants with different growth forms. - New Phytol. 175: 81-93, 2007.

Goltsev V., Zaharieva I., Chernev P. et al:: Drought-induced modifications of photosynthetic electron transport in intact leaves: analysis and use of neural networks as a tool for a rapid non-invasive estimation. - BBA-Bioenergetics 1817: 1490-1498, 2012

Gomes M.T.G., da Luz A.C., dos Santos M.R. et al.: Drought tolerance of passion fruit plants assessed by the OJIP chlorophyll $a$ fluorescence transient. - Sci. Hortic.-Amsterdam 142: 49-56, 2012.

Grammatikopoulos G., Kyparissis A., Manetas Y.: Seasonal and diurnal gas exchange characteristics and water relations of the drought semi-deciduous shrub Phlomis fruticosa L. under Mediterranean field conditions. - Flora 190: 71-78, 1995.

Grammatikopoulos G., Manetas Y.: Direct absorption of water by hairy leaves of Phlomis fruticosa and its contribution to drought avoidance. - Can. J. Bot. 72: 1805-1811, 1994.

Guha A., Sengupta D., Reddy A.R.: Polyphasic chlorophyll $a$ fluorescence kinetics and leaf protein analyses to track dynamics of photosynthetic performance in mulberry during progressive drought. - J. Photoch. Photobio. B 119: 71-83, 2013.

Kaiser W.M.: Effects of water deficit on photosynthetic capacity. Physiol. Plantarum 71: 142-149, 1987.

Kalaji H.M., Jajoo A., Oukarroum A. et al.: Chlorophyll a fluorescence as a tool to monitor physiological status of plants under abiotic stress conditions. - Acta. Physiol. Plant. 
38: 102, 2016.

Karavatas S., Manetas Y.: Seasonal patterns of photosystem 2 photochemical efficiency in evergreen sclerophylls and drought semi-deciduous shrubs under Mediterranean field conditions. - Photosynthetica 36: 41-49, 1999.

Koller S., Holland V., Brüggemann W.: Effects of drought stress on the evergreen Quercus ilex L., the deciduous Q. robur L. and their hybrid $Q . \times$ turneri Willd. - Photosynthetica 51: 574-582, 2013.

Lauriano J.A., Lidon F.C., Carvalho C.A. et al.: Drought effects on membrane lipids and photosynthetic activity in different peanut cultivars. - Photosynthetica 38: 7-12, 2000.

Lawlor D.W., Cornic G.: Photosynthetic carbon assimilation and associated metabolism in relation to water deficits in higher plants. - Plant Cell Environ. 25: 275-294, 2002.

Lawlor D.W., Tezara W.: Causes of decreased photosynthetic rate and metabolic capacity in water-deficient leaf cells: a critical evaluation of mechanisms and integration of processes. Ann. Bot.-London 103: 561-579, 2009.

Lazár D.: The polyphasic chlorophyll a fluorescence rise measured under high intensity of exciting light. - Funct. Plant Biol. 33: 9-30, 2006.

Lazár D, Nauš J.: Statistical properties of chlorophyll fluorescence induction parameters. - Photosynthetica 35: 121-127, 1998.

Matos M.C., Campos P.S., Ramalho J.C. et al. Photosynthetic activity and cellular integrity of the Andean legume Pachyrhizus ahipa (Wedd.) Parodi under heat and water stress. - Photosynthetica 40: 493-501, 2002.

Nogués S., Alegre L.: An increase in water deficit has no impact on the photosynthetic capacity of field-grown Mediterranean plants. - Funct. Plant Biol. 29: 621-630, 2002.

Oukarroum A., Madidi S.E., Schansker G., Strasser R.J.: Probing the responses of barley cultivars (Hordeum vulgare L.) by chlorophyll $a$ fluorescence OLKJIP under drought stress and re-watering. - Environ. Exp. Bot. 60: 438-446, 2007.

Oukarroum A., Schansker G., Strasser R.J.: Drought stress effects on photosystem I content and photosystem II thermotolerance analyzed using Chl $a$ fluorescence kinetics in barley varieties differing in their drought tolerance. - Physiol. Plantarum 137: 188-199, 2009.

Oukarroum A., Strasser R.J., Schansker G.: Heat stress and the photosynthetic electron transport chain of the lichen Parmelina tiliacea (Hoffm.) Ach. in the dry and the wet state: differences and similarities with the heat stress response of higher plants. - Photosynth. Res. 111: 303-314, 2012.

Petsas A., Grammatikopoulos G.: Drought resistance and recovery of photosystem II activity in a Mediterranean semideciduous shrub at the seedling stage. - Photosynthetica 47: 284-292, 2009.

Redillas M.C.F.R., Strasser R.J., Jeong J.S. et al.: The use of JIP test to evaluate drought-tolerance of transgenic rice overexpressing OsNAC10. - Plant Biotechnol. Rep. 5: 169$175,2011$.

Stirbet A., Govindjee: On the relation between the Kautsky effect (chlorophyll $a$ fluorescence induction) and Photosystem II: Basics and applications of the OJIP fluorescence transient. J. Photoch. Photobio. B. 104: 236-257, 2011.

Stirbet A., Lazár D., Kromdijk J., Govindjee: Chlorophyll $a$ fluorescence induction: Can just a one-second measurement be used to quantify abiotic stress responses? - Photosynthetica 56: 86-104, 2018.

Strasser R.J., Stirbet A.D.: Heterogeneity of photosystem II probed by the numerically simulated chlorophyll $a$ fluorescence rise (O-J-I-P). - Math. Comput. Simulat. 48: 3-9, 1998.

Strasser R.J., Tsimilli-Michael M., Qiang S., Goltsev V.: Simultaneous in vivo recording of prompt and delayed fluorescence and 820-nm reflection changes during drying and after rehydration of the resurrection plant Haberlea rhodopensis. - BBA-Bioenergetics 1797: 1313-1326, 2010.

Strasser R.J., Tsimilli-Michael M., Srivastava A.: The fluorescence transient as a tool to characterize and screen photosynthetic samples. - In: Yunus M., Pathre U., Mohanty P. (ed.): Probing Photosynthesis: Mechanisms, Regulation and Adaptation. Pp. 443-480. Taylor \& Francis, London 2000.

Strasser R.J., Tsimilli-Michael M., Srivastava A.: Analysis of the chlorophyll $a$ fluorescence transient. - In: Papageorgiou G.C., Govindjee (ed.): Chlorophyll $a$ Fluorescence: A Signature of Photosynthesis. Advances in Photosynthesis and Respiration. Pp. 321-362. Springer, Dordrecht 2004.

Tseliou E., Chondrogiannis C., Kalachanis D. et al.: Integration of biophysical photosynthetic parameters into one photochemical index for early detection of Tobacco Mosaic Virus infection in pepper plants. - J. Plant Physiol. 267: 153542, 2021.

Tsimilli-Michael M.: Revisiting JIP-test: An educative review on concepts, assumptions, approximations, definitions and terminology. - Photosynthetica 58: 275-292, 2020.

Tsimilli-Michael M., Strasser R.J.: In vivo assessment of plants' vitality: applications in detecting and evaluating the impact of mycorrhization on host plants. - In: Varma A. (ed.): Mycorrhiza: State of the Art. Genetics and Molecular Biology, Eco-Function, Biotechnology, Eco-Physiology, Structure and Systematics, $3^{\text {rd }}$ Edition. Pp. 679-703. Springer, BerlinHeidelberg 2008.

Turner N.C.: Techniques and experimental approaches for the measurement of plant water status. - Plant Soil 58: 339-366, 1981.

van Heerden P.D.R., Swanepoel J.W., Krüger G.H.J.: Modulation of photosynthesis by drought in two desert scrub species exhibiting $\mathrm{C}_{3}$-mode $\mathrm{CO}_{2}$ assimilation. - Environ. Exp. Bot. 61: 124-136, 2007.

Živčák M., Brestič M., Kalaji H.M., Govindjee: Photosynthetic responses of sun- and shade-grown barley leaves to high light: is the lower PSII connectivity in shade leaves associated with protection against excess of light? - Photosynth. Res. 119: 339-354, 2014.

Živčák M., Brestič M., Olšovská K., Slamka P.: Performance index as a sensitive indicator of water stress in Triticum aestivum L. - Plant Soil Environ. 54: 133-139, 2008.

Appendix 1. Steps for the calculation of photochemical drought index (PDI) according to the IBR method.

A. Calculation of the mean values (m) of chlorophyll fluorescence parameters $c f p$ and their standard deviations (sd) corresponding to each day of the experiment.

B. Calculation of the $\mathrm{Y}$ value (standardization) as $\mathrm{Y}=(\mathrm{m}-\mathrm{M}) / \mathrm{sd}$, where $\mathrm{Y}$ represents the standardized value of each chlorophyll fluorescence parameter (biomarker); $\mathrm{m}$ and sd are as previously defined and $\mathrm{M}$ is the mean value of each chlorophyll fluorescence parameter calculated for all the days of the experiment.

C. Calculation of $Z$ as: $Z=-Y$ or $Z=+Y$, if the effect of drought on the biomarker corresponds to an inhibition or a stimulation. 
D. Calculation of $S$ (Score) for each biomarker, where $S \geq 0$; this is done by adding to $Z$ the absolute (i.e., positive) value of the minimum of the standardized data, which is labeled $|\operatorname{Min}|: \mathrm{S}=\mathrm{Z}+|\operatorname{Min}|$.

E. The Scores for all the $c f p$ were then graphically depicted by radar plots (Fig. 6). Consequently, the PDI was calculated by summing up triangular star plot areas for each two neighboring $c f p$ data (Ferreira et al. 2015, Stirbet et al. 2018). In that case, the radius coordinate coincides with the Score of a given $c f p$ at a given date. It is critical for the accuracy of the method, the PDI calculations to be performed with exactly the same order of $c f p$ data for all the sampling times (days of experiment) and for species.

Appendix 2. Selected JIP-test parameters and their description based on data extracted from chlorophyll $a$ fluorescence transient.

\begin{tabular}{|c|c|}
\hline Fluorescence parameters & Description \\
\hline $\mathrm{F}_{0}$ & Minimum fluorescence, when all PSII reaction centers are open (O-step) \\
\hline $\mathrm{F}_{300 \mu \mathrm{s}}$ & Fluorescence intensity at $300 \mu \mathrm{s}$ (K-step) \\
\hline $\mathrm{F}_{\mathrm{J}}$ & Fluorescence intensity at $2 \mathrm{~ms}$ (J-step) \\
\hline $\mathrm{F}_{\mathrm{I}}$ & Fluorescence intensity at $30 \mathrm{~ms}$ (I-step) \\
\hline $\mathrm{F}_{\mathrm{m}}$ & Maximal fluorescence, when all PSII reaction centers are closed (P-step) \\
\hline Area & Total complementary area between OJIP curve and $\mathrm{F}=\mathrm{F}_{\mathrm{m}}$ \\
\hline $\mathrm{V}_{\mathrm{K}}=\left(\mathrm{F}_{300 \mu \mathrm{s}}-\mathrm{F}_{0}\right) /\left(\mathrm{F}_{\mathrm{m}}-\mathrm{F}_{0}\right)$ & Relative variable fluorescence at K-step \\
\hline $\mathrm{V}_{\mathrm{J}}=\left(\mathrm{F}_{\mathrm{J}}-\mathrm{F}_{0}\right) /\left(\mathrm{F}_{\mathrm{m}}-\mathrm{F}_{0}\right)$ & Relative variable fluorescence at J-step \\
\hline $\mathrm{V}_{\mathrm{I}}=\left(\mathrm{F}_{\mathrm{I}}-\mathrm{F}_{0}\right) /\left(\mathrm{F}_{\mathrm{m}}-\mathrm{F}_{0}\right)$ & Relative variable fluorescence at I-step \\
\hline $1 / \mathrm{V}_{\mathrm{I}}$ & Parameter indicating PSI end electron acceptors \\
\hline $1-V_{I}$ & Parameter indicating total active PSI reaction centers \\
\hline $\mathrm{V}_{\mathrm{K}} / \mathrm{V}_{\mathrm{J}}$ & Parameter indicating fluorescence rise at K step due to stress conditions \\
\hline $\mathrm{M}_{0}=4\left(\mathrm{~F}_{300 \mu \mathrm{s}}-\mathrm{F}_{0}\right) /\left(\mathrm{F}_{\mathrm{m}}-\mathrm{F}_{0}\right)$ & Approximated initial slope of the fluorescence transient \\
\hline $\mathrm{S}_{\mathrm{m}}=\operatorname{Area} /\left(\mathrm{F}_{\mathrm{m}}-\mathrm{F}_{0}\right)$ & $\begin{array}{l}\text { Normalized total complementary area above the OJIP transient reflecting total } \\
\text { electron carriers per RC }\end{array}$ \\
\hline \multicolumn{2}{|l|}{ Specific fluxes per reaction center $(\mathrm{RC})$} \\
\hline $\mathrm{ABS} / \mathrm{RC}=\left(\mathrm{M}_{0} / \mathrm{V}_{\mathrm{J}}\right) \times\left(1 / \varphi \mathrm{P}_{0}\right)$ & Absorption flux per RC of PSII \\
\hline $\mathrm{TR}_{0} / \mathrm{RC}=\mathrm{M}_{0} / \mathrm{V}_{\mathrm{J}}$ & Trapped energy flux per RC of PSII \\
\hline $\mathrm{ET}_{0} / \mathrm{RC}=\left(\mathrm{M}_{0} / \mathrm{V}_{\mathrm{J}}\right) \times\left(1-\mathrm{V}_{\mathrm{J}}\right)$ & Electron transport flux per RC of PSII \\
\hline $\mathrm{DI}_{0} / \mathrm{RC}=\mathrm{ABS} / \mathrm{RC}-\mathrm{TR}_{0} / \mathrm{RC}$ & Dissipated energy flux per RC of PSII \\
\hline \multicolumn{2}{|l|}{ Yields or flux ratios } \\
\hline$\varphi \mathrm{P}_{0}=\mathrm{TR}_{0} / \mathrm{ABS}=1-\mathrm{V}_{\mathrm{J}}$ & Maximum quantum yield of primary photochemistry \\
\hline$\psi \mathrm{E}_{0}=\mathrm{ET}_{0} / \mathrm{TR}_{0}=1-\mathrm{V}_{\mathrm{I}}$ & Efficiency with which a PSII trapped electron is transferred from $\mathrm{Q}_{\mathrm{A}}^{-}$to PQ \\
\hline$\varphi \mathrm{E}_{0}=\mathrm{ET}_{0} / \mathrm{ABS}=\varphi \mathrm{P}_{0} \times \psi \mathrm{E}_{0}$ & Quantum yield of electron transport from $\mathrm{Q}_{\mathrm{A}}^{-}$to $\mathrm{PQ}$ \\
\hline$\varphi \mathrm{D}_{0}=1-\varphi \mathrm{P}_{0}=\mathrm{F}_{0} / \mathrm{F}_{\mathrm{m}}$ & Quantum yield of energy dissipation \\
\hline$\delta \mathrm{R}_{0}=\mathrm{RE} / \mathrm{ET}_{0}=\left(1-\mathrm{V}_{\mathrm{I}}\right) /\left(1-\mathrm{V}_{\mathrm{J}}\right)$ & Efficiency with which an electron from $\mathrm{PQH}_{2}$ is transferred to final PSI acceptors \\
\hline$\varphi \mathrm{R}_{0}=\mathrm{RE} / \mathrm{ABS}=\varphi \mathrm{P}_{0} \times \psi \mathrm{E}_{0} \times \delta \mathrm{R}_{0}$ & Quantum yield of electron transport from $\mathrm{Q}_{\mathrm{A}}^{-}$to final PSI acceptors \\
\hline \multicolumn{2}{|l|}{ Performance index } \\
\hline $\mathrm{PI}_{\mathrm{ABS}}=(\mathrm{RC} / \mathrm{ABS}) \times \varphi \mathrm{P}_{0} /\left(1-\varphi \mathrm{P}_{0}\right) \times \psi \mathrm{E}_{0} /\left(1-\psi \mathrm{E}_{0}\right)$ & Performance index on absorption basis \\
\hline $\begin{array}{l}\mathrm{PI}_{\text {total }}=(\mathrm{RC} / \mathrm{ABS}) \times \varphi \mathrm{P}_{0} /\left(1-\varphi \mathrm{P}_{0}\right) \times \psi \mathrm{E}_{0} /\left(1-\psi \mathrm{E}_{0}\right) \times \\
\delta \mathrm{R}_{0} /\left(1-\delta \mathrm{R}_{0}\right)\end{array}$ & $\begin{array}{l}\text { Total performance index measuring the performance up to the PSI end electron } \\
\text { acceptors }\end{array}$ \\
\hline
\end{tabular}

(C) The authors. This is an open access article distributed under the terms of the Creative Commons BY-NC-ND Licence. 